\title{
An Analysis of Metonymy and Metaphor in Selected News Articles Related to Sports in The Jakarta Post
}

\author{
Indah Utami Chaerunnisah
}

English Language Studies, Graduate Program

Sanata Dharma University, Yogyakarta, Indonesia

\section{Article Info}

Article history:

Submitted Feb 20, 2020

Revised Feb 21, 2020

Accepted Oct 24, 2020

Published November 02, 2020

\section{Keywords:}

Cognitive Semantics

Metonymy

Metaphor

The Jakarta Post

\begin{abstract}
Since newspapers is a one way communication where they provide information and people receive it, the readers have to be able to understand the whole messages without the chance to clarify and to ask the other parties. This paper aims at revealing the type of metonymy and metaphor used in five selected news articles related to sports in The Jakarta Post, and describing why metonymy and metaphor are used in the news articles. Furthermore, this research is a qualitative research which aims at describing and discussing about the use of metaphor and metonymy in the news articles related to sports. The result revealed that there are only two types of metonymy found in the news articles namely represented entity for representative and whole for part where the most dominant type is represented entity for representative. Furthermore, all types of metaphor can be found in the data, but the most dominant type is structural metaphor. These articles tend to use represented entity for representative since it discusses about athletes and teams which play as the representative of their country. Meanwhile, the dominant use of structural metaphor because the writer tend to describe the athletes and teams as another concrete object.
\end{abstract}

Corresponding Author:

Indah Utami Chaerunnisah

English Language Studies, Graduate Program

Sanata Dharma University, Yogyakarta, Indonesia

Jl. Affandi, Caturtunggal, Depok, Sleman, Yogyakarta

Email: indahutamich@gmail.com

\section{INTRODUCTION}

In everyday life, communication plays a significant role and holds many important functions. People communicate to express their ideas, to share information, to explain events and experiences, to build and maintain relationship, and to exchange goods and services. These functions are carried out through the exchange of meaning between two or more parties in the interaction. One of several means of communication is through verbal language. In verbal language, it is important to deliver clear messages so that people would not misunderstand. According to Griffiths (2006), there are two types of meaning in communication namely sender's meaning and utterance's meaning. Sender's meaning is the intended message the speaker wants to deliver while utterance's meaning is the possible meanings people might interpret from the utterance. Therefore, all parties in the interaction have to possess the same reference to ensure that the messages are delivered successfully.

Furthermore, the meaning and concept that people have in their head are expressed through linguistic devices such as words and phrases. These meanings are understood through categorization and groupings. For example when someone talk about a jeep, people would categorize it as a means of transportation which is a part of the car 
groups (Radden \& Dirven, 2007). However, human's concepts and ideas are extremely extensive and so abstract that the existing categories cannot be used to express all of them. Therefore, the meaning is extended through metonymy and metaphor. While through categorization, the meanings are literal, in metonymy and metaphor, the meaning is denotative i.e. the opposite of literal meaning.

Lakoff and Johnson (1980) defines metaphor as a way to understand an abstract concept through another familiar concept through resemblance. They propose an example where love is seen is a journey. Here, love as an abstract concept is understood through the concept of journey which people are more familiar with (Rambaud, 2012). An example of this is the metaphor We are going nowhere in our relationship. Meanwhile, although metonymy is also a form of meaning extension, it is different with metaphor since it bases on the concept of association. While metaphor is based on "similarity", metonymy is based on "contiguity" (Lakoff \& Johnson, 1980). An example of metonymy is when someone is important and clever is called a brain. Furthermore, the extension of meaning through metonymy and metaphor leads to words and phrases having different meanings. As seen in the examples above, the word brain and the phrase going nowhere have at least two different meanings which are the literal and the non-literal ones. Because of this, people might have a hard time understanding the message since they have to determine which one is the meaning of the utterance. Therefore, it is significant for people to understand metaphor and metonymy so that they can communicate effectively and achieve their goal successfully.

Furthermore, people use metonymy and metaphor in almost every parts of their life, and one of them is in newspapers. Since newspapers is a one way communication where they provide information and people receive it, the readers have to be able to understand the whole messages without the chance to clarify and to ask the other parties. In addition, newspapers are designed to be released for public and the language used is customized for the mass. In other words, it is not made to fit each individual so sometimes there are words which are difficult for certain readers to comprehend especially metonymy and metaphor. Among many news articles, those related to sports are the ones which frequently use metonymy and metaphor. The use of metonymy and metaphor is essential as they have the ability to summarize all the feelings and "nuances" the writer want to the deliver in only several words (Noprianshah \& Apriliana, 2015). Therefore, in this paper, the researcher is going to analyse metonimies and metaphors used in five news articles related to sports taken from The Jakarta Post news website.

Following the backgrounds of the problem above, this paper aims at 1) revealing the type of metonymy and metaphor used in the news articles, and 2) describing why metonymy and metaphor are used in news articles related to sport. This research will hopefully be beneficial and significant for several parties. First, it will be beneficial for the English studies and English Literature students especially those who are interested in linguistic research since this paper can enhance their knowledge and understanding on cognitive semantics especially on the concept and application of metonymy and metaphor. Second, it will be significant for other researchers especially those who want to conduct a research in cognitive semantics because they can use this paper as a bibliographical reference, and it can also motivate others to conduct similar researches. Lastly, this paper will be beneficial for people and the readers in general. This is because this paper can give them a further explanation and a deeper understanding of metonymy and metaphor especially the ones used in news articles related to sports. 


\section{THEORY AND METHODS}

\section{Cognitive Semantics/Linguistics}

Basically, cognitive semantics/linguistics centres on the idea that language and human thought are inseparable (Radden \& Dirven, 2007). Cognitive linguists believe that cognition process is closely related to linguistic expressions and lexical choices uttered in a communication process. Further, they argue that people use language to organize and categorize various things and concepts around them (Rambaud, 2012). In other words, people use language to express the concepts and meanings in their mind. In cognitive linguistics, there are three significant concepts namely category, metonymy and metaphor.

People understand meanings and abstract theories mainly through categories. Following Dirven and Radden (2007), a category is understood as a collection of "similar experiences" which is 'relevant and meaningful' to a certain community. Sometimes, the category can be personalized, but most of the time, it is made public. In other words, the category is understood and shared by a certain community, by most if not all people in the society. In addition, categories are usually influenced by several things such as place, culture, education and beliefs. For example, in tropical countries where coconuts are abundant, people utilize every part of it, so they create a category which consists of many varieties and parts of coconut. Meanwhile, in non-tropical countries where there are no coconuts, they have a very limited lexical categories related to coconuts.

\section{Metonymy}

Griffiths (2006: 85) defines metonymy as referring to something or someone using its other parts which is related to it. Related to metonymy, Rambaud (2012: 208) argues that metonymy is an easy way of using referent and is used to "highlight associative relation". While in conceptual categories discussed previously, words are understood through their literal and denotative meaning, in metonymy, the meaning is non-literal or connotative. In other words, the meaning is not the one taken from dictionaries, but rather it has to be understood through an association of that certain word. Dirven and Radden (2007) describe metonymy as a conceptual shift where the concept of a certain word shifted from its original meaning to another concept which is different but still associated and has the same characteristics as the original meaning. In addition, this conceptual shift still operates in a single domain (Shue, 2010)which makes it relatively easy for people to guess the meaning and understand the message of the utterance.

Furthermore, following Rambaud (2012), there are several types of metonymy which are container for contained, possessor for possessed, represented entity for representative, whole for part, part for whole and place for institution.

\section{Metaphor}

Similar to metonymy, metaphor is also a form of figurative language. It was mainly used in various text which employs poetic expressions such as poems, prose, short stories and novels. However, Lakoff and Johnson (1980) argue that every part of human language are metaphorical, that human thought are mostly metaphorical. Before going further, first, it is important to understand the meaning of metaphor. Following Lakoff and Johnson (1980), metaphor is a way of understanding an abstract concept and ideas through another concept of structure which is more concrete and familiar. In other words, metaphor is used to explain difficult and complicated things through another one which is easier to comprehend.

Further, Rambaud (2012) explains that metaphor involves three elements which are source domain, target domain, and a set of correspondences. Source domain is usually 
"concrete and familiar", and target domain is usually "abstract and less structured". In relation to this, one of the differences between metonymy and metaphor lies in the number of domain involved in meaning making and understanding process. While metonymy involves only one domain, metaphor as mentioned before involves two to three different domains. In addition, another significant difference between metaphor and metonymy lies in the relation between meanings in which metonymy is based on association (Šarić, 2016), while metaphor is based on resemblance.

Furthermore, there are several types of metaphor according to Lakoff and Johnson (1980), which are structural metaphor, orientational metaphor and ontological metaphor. Lakoff and Johnson (1980) define structural metaphor as a way of understanding a complicated and less structured concept through an easier and more structured concept. Here, the source domain has more elaborate information compared to the ones in the target domain. Futher, as the name suggest, orientational metaphor creates an orientation or a set of meaning by making them more similar to each other (Lakoff and Johnson, 1980). Usually, this kind of metaphor involves spatial relation such as up-down, frontback, on-off, central peripheral and etc. Moreover, compared to structural metaphor which provides more structured concepts for the target domain, ontological metaphor only tries to make meaning more comprehensive by making an abstract and complicated ideas and concepts more familiar and concrete (Lakoff and Johnson, 1980). This is done through representation where abstract concepts are represented by concrete objects, ideas, activities and people.

\section{Methods}

In conducting a research, first, it is significant for researchers to decide the type of study before starting the data collection. This is because it will affect many aspects in the research including type of data, the process of data analysis, and the findings as well as the discussion. Basically, there are two types of study namely quantitative and qualitative study. Sometimes people combine these two, but many times they focus on one type since each of them has different objectives and research outcome. In relation to this, this research is a qualitative research. Following Vanderstoep and Johnston (2006:167), a qualitative research tries to provide a thorough discussion and an in-depth explanation about a certain topic under the study. This research aims at describing and discussing about the use of metaphor and metonymy in selected sports related news articles in The Jakarta Post. Its objectives are to give a deeper understanding and a clearer insight about the use of cognitive semantics or more specifically metonymy and metaphor in the real settings especially in news articles.

Furthermore, the data in this study were collected from selected news article taken from the website of The Jakarta Post. The form of data are words and phrases from the writer and utterances of people in the news articles. The data collection was done through a close reading where the researcher read the news and selected the words and phrases which are categorized as metonymy or metaphor. After collecting the data, the researcher categorized the data following the types of metonymy and metaphor proposed by Radden and Dirven (2007). To make the data analysis easier, she numbered the data and put them into a data sheet.

After the data collection process was completed, the researcher started analyzing the data. In this process, the researcher examined the data in the data sheet, and read them closely. The data were then interpreted, and the researcher gave explanation for each data collected in the data sheet. Further, the data and its interpretation and explanation went through a triangulation to avoid mistakes and errors and to ensure that 
the data were collected and analyzed correctly. After the triangulation, the data and explanation were revised following the feedback and suggestions. Finally, the researcher drew conclusion based on the findings and results of the research.

The trustworthiness of the study was ensured through a triangulation. Denzin in Jensen and Jakowski (20015: 62) argues that there are four types of triangulation namely triangulation by theory, triangulation by data, triangulation by method and triangulation by other researchers. In this research, two triangulation techniques were applied which are triangulation by theory and by other researchers. First, the researcher referred to the theory of cognitive semantics especially metonymy and metaphor from various books and experts. Second, she consulted the lecturer and other researchers to ensure the trustworthiness and the validity of the data.

\section{RESULT AND DISCUSSION}

After analysing the metonymies found in the news articles related to sports in The Jakarta Post, not all types of metonymy are used by the writer, and the frequency of the data is also different. The number of data, the frequency and the percentage is illustrated in the table below:

Table 1. Types of Metonymy in the News Articles Related to Sports in The Jakarta Post

\begin{tabular}{llcc}
\hline No. & \multicolumn{1}{c}{ Types of Metonymy } & Frequency & Percentage \\
\hline 1. & Container for Contained & - & - \\
\hline 2. & Possessor for Possessed & - & - \\
\hline 3. & Represented Entity for Representative & 10 & $71 \%$ \\
\hline 4. & Part for Whole & 4 & $29 \%$ \\
\hline 5. & Whole for Part & - & - \\
\hline 6. & Place for Institution & - & - \\
\hline & Total & 14 & $100 \%$ \\
\hline
\end{tabular}

In the table 1, it can be seen that there are only two types of metonymy found in the five selected news articles namely represented entity for representative and whole for part. The most dominant type is represented entity for representative with 10 out of 14 data and $71 \%$ occurrence, followed by the part fro whole with 4 out of 14 data or $29 \%$ occurrence.

Further, following Lakoff and Johnson (1980), there are three types of metaphor namely structural metaphor, orientational metaphor, and ontological metaphor. After analysing the metaphor used in the five selected news articles, it is revealed that all types of metaphor were employed by the writer. However, the frequency of each type is different. The table below illustrate the types of metaphor, the frequency and the percentage of each type.

Table 2. Types of Metaphor in the News Articles Related to Sports in The Jakarta Post

\begin{tabular}{llcc}
\hline No. & Types of Metaphor & Frequency & Percentage \\
\hline 1. & Structural Metaphor & 14 & $44 \%$ \\
\hline 2. & Orientational Metaphor & 7 & $22 \%$ \\
\hline 3. & Ontological Metaphor & 11 & $34 \%$ \\
\hline & Total & 32 & $100 \%$
\end{tabular}

In table 2, it can be seen that all types of metaphor can be found in the data, but their frequencies are different. The most dominant type is structural metaphor with 14 out of 
32 data or $44 \%$ occurrences. It is followed by ontological metaphor which occur in 11 out of 32 data or $34 \%$ occurrences. The last is orientational metaphor with 7 out of 32 data or $22 \%$ occurrences. The frequency of each type is relatively similar where there is no big gaps between one type to another.

\section{Metonymy}

\section{Represented entity for representative}

As the name suggests, represented entity for representative means that a community or a nation is represented by an entity or a team, but it is referred as the name of the community or nation being represented. In the five selected news articles, there are several examples of this type of metonymy, below is one of them:

(1) Lionel Messi heads into the Copa America this weekend as the competition's main attraction but one with a desperate need to end more than a decade of hurt with Argentina.

In the example above, the sentence talks about Lionel Messi who plays for Argentina in their national football team. Here, the metonymy is Argentina. This word does not actually refer to Argentina as the whole nation and people, but it refers to its national football team which is the representative of the nation. Here, the meaning is shifted from Argentina as a whole nation to Argentina as a football team. However, it is still in a single domain which is Argentina. Often, in sports, or more specifically in football, people refer to the team using the name of their country only, without adding words such as 'footbal team' to the name. This plays a vital role in creating a patriotic emotion within the players as well as in gaining support from the public in their country. This creates an effect where the team's win is not only theirs, but also their country's pride and the people in it. In other words, the use of metonymy have a significant impact toward people's thought, feelings and emotion. Furthermore, another example of this type is provided below:

(2) Mastercard canceled a Neymar-themed ad campaign that was to be broadcasted during the Copa America, Spanish media reported, while Nike expressed its "deep concern" on Monday.

Example (2) above discusses about the controversy surrounding Neymar, a widelyknown football player, where he was accused of raping a woman. As an effect of the controversy, several sponsors who have support Neymar lately have taken various actions and have shown different response. In this example, the metonymy is Mastercard. The sentence above explains how Mastercard has cancelled its sponsorship for Neymar. Here, the word Mastercard indeed refer to the company, but in reality, the one who have taken the action is a representative of the company. This is a metonymy because only a single domain is involved which is Mastercard. The use of metonymy in this kind of situation is essential to avoid giving responsibilities to one only one person, in case there is a negative effect from it. Further, it is also to indicate that the decision is a result of the company's discussion and consideration, not only an individual's decision.

\section{Part for whole}

Part for the whole metonymy is when a part of an object or a concept is used to refer to the whole thing or concept. After analysing the metonymy in the news articles, there are several data which are categorized in this type of metonymy. One of them is provided below:

(3) The third seed now has a stunning 92-2 win-loss record on the Paris clay, having beaten Federer for the sixth time in as many French Open meetings despite difficult, windy conditions. 
The example above discusses about Rafael Nadal who is currently one of the top tennis players. Specifically, it is talking about Nadal's achievement in the French Open. In this sentence, the metonymy is the Paris clay. This phrase does not actually mean the clay in Paris, but it refers to the tennis field where the clay ground is a part of it. This metonymy is understood by looking at the association between the clay and the field which are both still in a single domain. Further, to get a clearer explanation, below is another example:

(4) Neymar's injury also leaves a question mark over the future career of a player who cost Qatar-owned Paris Saint-Germain a world-record fee of 222 million euros (\$248 million) when he moved from Barcelona in 2017.

The sentence in example (4) talks about the effect of Neymar's injury towards his career as a football player following his recent controversy. In this example, the metonymy is a question mark. The phrase leave a question mark means that the injury makes people question the future of his career in football. The metonymy is used to refer to the whole act of questioning. Since it is a part of a question, it still operates in a single domain.

\section{Metaphor}

\section{Structural metaphor}

Structural metaphor is a way of explaining and understanding a less structured and unfamiliar concept through another one which is more structured and familiar (Sánchez, Moreno, \& Velasco, 2012). Lakoff and Johnson (1980) state that this type of metaphor usually use a target domain which has more elaborated information. After analysing metaphor in the five selected news articles, there are many data which belong to this type. Below is one of the examples:

(5) Jonatan, who won the New Zealand Open last month, set himself up for a back-to-back triumph after ousting top seed Chou Tien-chen of Taiwan 22-20, 13-21, 21-16 in the semi-finals in Australia yesterday.

The sentence above talks about Jonatan Christie's win in the New Zealand Open after beating Chou Tien-chen from Taiwan. The metaphor here is top seed which is used to describe Chou Tien-chen. This phrase does not actually mean that he is a seed, but rather it refers to him as a top promising athlete who is very talented and has the potentials to grow. Here the source domain is 'a part of a plant' which is a seed, and the target domain is human or more specifically Chou Tien-chen. The use of top here is to indicate his position in badminton, and the use of seed is to give a nuance that with proper care and training, he is someone who has the potential grow into an exceptional player in the future. On the other hand, this metaphor also emphasizes and highlights Jonatan's ability. It implies that Jonatan must have a better skill and potential as he was able to conquer such good player. Another example of structural metaphor is presented as follows:

(6) As he made his way out through a media scrum after giving his statement to police, the star striker expressed gratitude to his fans for their support.

In example (6) above, the sentence discusses about Neymar's controversy where he was accused of raping a woman in a hotel in Paris. Specifically, it talks about his press conference regarding the issue. Here, Neymar is described as a star to illustrate his fame and talent in football. This metaphor involves a source domain which is the star and a target domain which is Neymar. These two different domains are related since their characteristics are similar: bright and is at the top. Further, this metaphor also works as 
an irony. As someone who is being looked up to by many of his fans, his action might impact a lot of people. Therefore, his wrongdoings become more serious and shameful.

After analysing and discussing about the examples above, it can be seen that structural metaphor in news articles related to sports is mainly used to give another name or an alias to the athlete. This is to provide better explanation and a deeper understanding to the readers regarding the athletes and their team in their respective field. These metaphors also help the readers to undertstand the athletes' skill, popularity, struggle and potential. With these understanding, it can invoke their emotion and their will to support the athletes.

\section{Orientational metaphor}

In this metaphor, the target domain and the source domain are made more similar to each other. It usually involves spatial relation such as on-off, in-out, and up-down. In the findings, there are several data which is categorized as an orientational metaphor. An example of this metaphor is presented below:

(7) And the 31-year-old knows he's running out of time to rectify that anomaly.

In the example above, the sentence discusses about Messi's determination to end Argentina's title drought in the world's football competitions. The metaphor in the example above is running out of time, and is categorized as an orientational metaphor since it involves spatial relation; out. This phrase does not literally mean that time is running here and there like what human do, but it means that the clock is ticking and there is not much time left for Messi to make Argentina be back at the top position. The use of this metaphor is to give more suspense and the sense of urgency to the reader as it describes the time as running which will happen quickly. Furthermore, another example of orientational metaphor is provided below:

(8) But the disappointments have kept piling up despite a 10th La Liga crown secured in May.

The sentence in example (8) above is from the same article as the previous example which explains about Messi's eagerness to help Argentina win in the international football competition. This sentence describes how Messi and Argentina's supporters are disappointed due to the title drought in the last decade. Here, the metaphor is piling up. The phrase involves spatial relation; $u p$ which is why it is categorized as an orientational metaphor. Piling up is used to describe concrete objects, but here, it is used to explain about disappointment which is an abstract feeling. This metaphor is give more emphasis and pressure to the team as people have hopes on them, and the supporters' disappointments are growing more and more each day.

\section{Ontological metaphor}

Lakoff and Johnson (1980) describes ontological metaphor as a metaphor which tries to make the abstract object more concrete by giving them characteristics of tangible objects such as being countable and measurable. After analysing metaphor in the news articles, there are more than ten data which belongs to this type of metaphor. Below is one of the examples:

(9) A tally of just nine games meant it was Federer's heaviest defeat in a Grand Slam match since managing only four against Nadal in their famously one-sided 2008 Roland Garros final.

Example (9) talks about Nadal's win against Federer in the French Open Final. It explains about how Nadal made Federer experience his heaviest defeat during his career as a tennis player. The metaphor heaviest defeat is categorized as an ontological metaphor since it makes the event defeat which is an abstract concept seems like 
something concrete which is measurable. The defeat is illustrated as something which can be measured through weight hence it is described as the heaviest defeat. Hence, the use of this metaphor give emphasis on how bad the defeat is, so that the reader can understand what the player is going through. In addition, another example of this type of metaphor is provided below:

(10) But Nadal grabbed a 4-2 advantage in a marathon sixth game as Federer, looking to become the oldest Grand Slam finalist since Ken Rosewall at the 1974 US Open, dumped a forehand into the net.

The sentence in example (10) above is from the same article as the previous example which discusses about Nadal's win against Federer. Specifically, it explains about their match in the final of the $12^{\text {th }}$ French Open. Here, the metaphor is grabbed which is usually applied to describe activities related to tangible object. However, in the sentence above, this word is used along with an abstract concept which is less structured and familiar. Therefore, it is categorized as an ontological metaphor. Further, the use of this metaphor give a sense that Nadal get the advantage through hard work and determination. It is not something that he receive, but rather a fruit of his effort, something he get through his own hand.

\section{CONCLUSION}

Finally, after analysing the data of metonymy and metaphor in five selected news articles related to sports in The Jakarta Post, based on the objectives of the research, two conclusions can be drawn. First, the result revealed that there are only two types of metonymy found in the five selected news articles namely represented entity for representative and whole for part. The most dominant type is represented entity for representative with 10 out of 14 data and $71 \%$ occurrence, followed by the whole for part with 4 out of 14 data or $29 \%$ occurrence. Furthermore, all types of metaphor can be found in the data, but their frequencies are different. The most dominant type is structural metaphor. Moreover, news articles related to sports tend to use represented entity for representative since it discusses about athletes and teams which play as the representative of their country. Meanwhile, the most dominant metaphor used is structural metaphor because the writer tend to describe the athletes and teams as another concrete object to help the reader understand more about their skill, potential and position in their respective fields.

\section{REFERENCES}

Griffiths, P. (2006). An introduction to English semantics and pragmatics. Edinburgh: Edinburgh University Press Ltd.

Jensen, K. B. (1991). A handbook of qualitative methodologies for mass communication research. London: Routledge.

Lakoff, G., \& Johnson, M. (1980). Metaphors we live by. Chicago: The University of Chigaco Press.

Noprianshah, \& Apriliana, W. S. (2015). An analysis of metonymy in column world of Jakarta Post newspaper. Literary Criticism Journal Vol. 2, No.2, 107-119.

Radden, G., \& Dirven, R. (2007). Cognitive English grammar. Philadelphia: John Benjamin B. $\mathrm{V}$. 
Rambaud, M. G. (2012). Basic semantics. Madrid: Universidad Nacional De Educación A Distancia.

Sánchez, M. T., Moreno, J. M., \& Velasco, J. A. (2012). Grasping metaphoric and metonymic processes in terminology. The Journal of Specialised Translation, 187-205.

Šarić, A. (2016). Metonymies in textbooks intended for teaching German for specific purpose at the Faculty of Food Technology. Macrothink: International Journal of Linguistics, Vol. 8, No.6, 233-243.

Shue, J.-S. (2010). Metaphors and metonymies in New York Times and Times Supplement News Headlines. Elsevier: Journal of Pragmatics, 1318-1334.

Vanderstoep, S., \& Johnston, D. (2009). Research method of everyday life. San Fransisco: Jossey-Bass. 